\title{
Happiness, Subjective Well-Being, and Life Satisfaction: A Compared Study between Long-Lived Elderly People in Northeast and Southeast Brazil
}

\author{
Raisa F. M. Simões ${ }^{1}$, Júlia C. L. Nóbrega ${ }^{1}$, Juliana Barbosa ${ }^{1}$, Tácila T. M. Santos ${ }^{1}$, Ricardo A. Olinda ${ }^{1}$, Tarciana N. \\ Menezes $^{1}$, Yeda A. O. Duarte ${ }^{2}$, Mayana Zatz ${ }^{3}$, Leandro U. Alves ${ }^{1,3} \&$ Silvana Santos $^{1}$ \\ ${ }^{1}$ Programa de Pós-Graduação em Saúde Pública, Universidade Estadual da Paraíba, Campina Grande, Paraíba, \\ Brazil \\ ${ }^{2}$ Departamento de Enfermagem, Faculdade de Saúde Pública, Universidade de São Paulo, São Paulo, Brazil \\ ${ }^{3}$ Departamento de Genética e Biologia Evolutiva, Universidade de São Paulo, São Paulo, Brazil \\ Correspondence: Dr. Silvana Santos, Mestrado em Saúde Pública, Universidade Estadual da Paraíba, Rua \\ Baraúnas, Bairro Universitário, 58429500, Campina Grande, PB - Brazil.
}

Received: November 2, 2020 Accepted: November 25, 2020 Online Published: December 8, 2020

doi:10.5539/gjhs.v13n1p89 URL: https://doi.org/10.5539/gjhs.v13n1p89

\begin{abstract}
This cross-sectional study aims to investigate and compare factors associated with happiness, subjective well-being, and life satisfaction in elderly people aged 80 and older in two different regions of Brazil. Face-to-face interviews were performed with 417 Brazilians aged 80 years and older, 179 from Northeast and 238 from the Southeast. The prevalence of feelings of happiness, subjective well-being, and overall life satisfaction were very similar for the older elderly in both regions. While in the Southeast, the predictive factors were literacy, higher income, and better economic situation, with many elderly people living alone; in the Northeast, the affective ties with more people seem to predominate, as well as having a more frequent and diverse support network, and practice leisure activities. Our findings support a view of social bonds and family support enables the older elderly people to feel more satisfied with life, performing activities that bring happiness and subjective well-being.
\end{abstract}

Keywords: Happiness, subjective well-being, aging, public health, developing countries

\section{Introduction}

Since the 1940s, the World Health Organization (WHO) has broadened its understanding of the concept of health by reviewing its indicators, postulating that health is a state of complete physical, mental and social well-being. Thus, the concept of subjective well-being gained space in scientific literature and became a health indicator with different instruments to measure it. Subjective well-being means the assessment of people about their lives, grouping cognitive and affective components such as happiness, life satisfaction, positive feelings and low negative feelings (Diener \& Tay, 2015). WHO itself has created an instrument called WHO-5, known as the "Welfare Index", as a parameter for measuring and comparing data between different populations.

In addition to subjective well-being, research has used other similar or associated concepts such as happiness and life satisfaction. Happiness is understood to be a positive psychological state resulting from the degree to which a person enjoys life, and life satisfaction can be considered a synonym for this, encompassing an overall assessment of life that involves all the criteria that involve the human mind (Veenhoven, 2015). Other scales were also created to measure these parameters such as the "Subjective Happiness Scale" (Lyubomirsky \& Lepper, 1997) and the "Global Life Satisfaction Scale" (Cantril, 1966).

Changes in health, in addition to improvements in living conditions, especially after the second half of the twentieth century, an increase in life expectancy, lower mortality and lower fertility were verified, defining a process of demographic transition that led to a continual increase in the proportion of elderly people in the world, which leads to longer lifespan (OPAS, 2017). As a developing country, Brazil has followed the demographic transition, and is one of the fastest-growing countries in terms of population age. It was estimated that in 1995 there were $4.7 \%$ people aged 60 years and over in the total population of the country (Miranda, da Cruz Gouveia Mendes, $\&$ da Silva, 2017), and, according to IBGE, in the last census conducted in 2010 , this contingent increased to $7.4 \%$, 
with $1.54 \%$ of older elderly people (aged 80 and over).

Given the recognition of the population aging process in Brazil, several laws and policies were created seeking to ensure social rights and promote the social integration of the elderly, valuing their autonomy and participation. In fact, the development of public policies for the elderly has been featured on the agenda of international health organizations regarding the proposition of guidelines for nations that still need to implement social and assistance programs to meet the emerging needs of this population group (OPAS, 2017).

At the beginning of the 21st century, the Pan American Health Organization (PAHO), in partnership with Argentina, Cuba, Uruguay, Barbados, Mexico, Chile, and Brazil, developed research on the health of the elderly known as the SABE Study (Health, Aging, and Well-being) to respond to the need for specialized information, as well as indicators on the various spheres of life and health of the elderly. In Brazil, this study has become a cohort study with over 2,000 elderly people evaluated every five years (Lebrão \& Laurenti, 2005). In recent years, this study has expanded its collaborative network to conduct studies on aging and longevity processes in high consanguineous communities of Northeastern Brazil. There was also interest in broadening the study of other populations with vulnerability characteristics and biological characteristics different from those previously studied. This multicenter survey allowed to collect systemic information about the living conditions and health of the elderly, and has been important to propose new goals and specific care policies for this population.

From this scenario in which a longer lifespan is observed and from the range of factors involved in the health of an individual, including the insertion of subjective indicators of health, it is worth questioning: Does subjective well-being, happiness and life satisfaction contribute to increase the life expectancy of individuals? Do long-lived populations differ from these indicators, such as those living in poor regions of the Northeastern backcountry compared to other urban populations that did not have so many restrictions?

A few studies have been conducted in Brazil seeking to associate living conditions of older elderly people and the degree of happiness, subjective well-being, and life satisfaction. Therefore, it is relevant to understand the factors that lead to healthy aging and greater longevity, since these factors play a very relevant role in the Brazilian context, given the rapid process of demographic and epidemiological transition that the country is going through.

In this paper, the objective is to investigate, understand and compare the factors associated with subjective well-being, life satisfaction, and happiness in two different older elderly populations: one in Northeast Brazil and one in Southeast Brazil, explaining the differences and specificities and suggesting associations between subjective factors and indicators.

\section{Methods}

This study is a cross-sectional, descriptive and analytical design. It was carried out in two locations: in a rural area in the Northeastern Brazilian backlands, in the state of Paraíba, in 2017, and in an urban region of southeastern Brazil, in the state of São Paulo, in the last cohort in 2015. The inclusion criteria was people aged 80 years or older residing in the area at the time of collection, and having answered all questions of self-assessment and the scales used in the dependent variables (happiness, subjective well-being and overall life satisfaction) on their own, without the help of an informant or substitute. Out of 179 respondents in the Northeast, 135 was included in the sample for the variable happiness, 134 elderly participants for the variable subjective welfare, and 140 elderly participants for the variable overall life satisfaction. In the Southeast region, out of 238 respondents, 208 was included in the analysis for the variable happiness, 202 elderly people for well-being, and 224 elderly participants for the variable global life satisfaction were totaled.

The Health, Aging, and Well-being - SABE questionnaire has been applied for twenty years in São Paulo (SABE-SP). In Paraíba, the questionnaire was adapted to local conditions with the removal of some items, but continues to encompass the eleven sections of the last version (A15), which covers various aspects of the elderly people's life and health, such as: personal data, cognitive assessment, health status, functional status, medications, use and access to services, family and social support network, work history and sources of entry, housing characteristics, anthropometry, flexibility and mobility.

The data was collected by interviewees, in both regions, at the homes of the participants after explaining the aims of the study. On agreeing, they signed the Informed Consent Form. Thus, the research is in accordance with the ethical aspects involving research with human beings, in accordance with Resolution number 466/2012 of the National Health Council of the Ministry of Health.

The dependent variables were happiness, subjective well-being, and overall life satisfaction. To analyze the self-perception of happiness, only the first question of the Happiness Scale was used. To investigate the level of subjective well-being, the entire WHO5 (Adapted) instrument (WHO) was used. To study overall life satisfaction, 
we used the question on overall life satisfaction (questionnaires attached). Independent variables include gender, age, self-reported ethnicity, literacy, marital status, income adequacy, family economic status in childhood, starvation in childhood, co-residence, self-rated health, number of chronic noncommunicable diseases, medication use, depressive symptoms, physical activity, importance of religion, smoking, taking walks or leisure, having pets, importance and interference of animals in the mood, living with other people in daily life, home arrangements, family and social support network, and role of the elderly person in this network, offering and/or receiving support.

Data were tabulated in the Epidata 3.1 double data entry program. The statistical software $\mathrm{R}$ was used for descriptive analysis showing the frequency of the data, and in order to identify associations between the variables, the initial multiple logistic regression model was adjusted with all variables taking as an association measure the odds ratio (OR) and confidence intervals at 95\% (IC95\%). Adjustment variables with $p \leq 0.20$ in the initial model were included in the final multiple analyses. In the interpretation of the regression results, $p<0.05$ was considered as indicating a statistically significant association for the dependent variable.

\section{Results}

Regarding sociodemographic characteristics, the two populations studied show a very different profile. In rural Northeastern Brazil, there is a predominance of older females (54.7\%) compared to males (45.3\%), and most of them had no access to formal education $(62 \%)$ and live with up to one minimum wage (67\%). The vast majority (86\%) lives in the company of other people, especially spouses and children; only $14 \%$ lived alone. Regarding the older elderly in the southeastern urban center, a higher predominance of women (70.6\%) was observed. Most of the elderly had self-reported white ethnicity $(61.7 \%)$, with good literacy conditions $(78.7 \%)$ and income $(57.8 \%)$; and live mainly with their children. In the Southeast there is almost twice the proportion of the elderly people $(27.3 \%)$ living alone than in the Northeast (Table 1).

Table 1. Profile of elderly people aged 80 years and older in the Northeast (PB) and Southeast (SP) regions regarding sociodemographic characteristics, health aspects and lifestyle. SABE-SP study, 2015 / SABE- PB, 2017

\begin{tabular}{|c|c|c|c|c|c|c|c|}
\hline Brazilian Populations & SABE Study & PB & & & SP & & \\
\hline Variables & Categories & $\mathbf{N}$ total & $\mathbf{n}$ & $\%$ & $\mathrm{~N}$ total & $\mathbf{n}$ & $\%$ \\
\hline \multicolumn{8}{|l|}{ Dependent } \\
\hline \multirow{2}{*}{ Happiness } & Most happy & \multirow{2}{*}{135} & 97 & 71.9 & \multirow{2}{*}{-208} & 150 & 72.1 \\
\hline & Less happy & & 38 & 28.1 & & 58 & 27.9 \\
\hline \multirow{2}{*}{ Subjective Well-being } & Best well-being & \multirow{2}{*}{-134} & 103 & 76.9 & \multirow{2}{*}{-202} & 159 & 78.7 \\
\hline & Worst well-being & & 31 & 23.1 & & 43 & 21.3 \\
\hline \multirow{2}{*}{ Overall Life Satisfaction } & High satisfaction & \multirow{2}{*}{140} & 122 & 87.1 & \multirow{2}{*}{224} & 181 & 80.8 \\
\hline & Low satisfaction & & 18 & 12.9 & & 43 & 19.2 \\
\hline \multicolumn{8}{|l|}{ Independent } \\
\hline \multirow{2}{*}{ Gender } & Feminine & \multirow{2}{*}{179} & 98 & 54.7 & \multirow{2}{*}{-238} & 168 & 70.6 \\
\hline & Masculine & & 81 & 45.3 & & 70 & 29.4 \\
\hline \multirow{2}{*}{ Age } & $80-89$ years & \multirow{2}{*}{179} & 142 & 79.3 & \multirow{2}{*}{-238} & 173 & 72.7 \\
\hline & 90 or more years & & 37 & 20.7 & & 65 & 27.3 \\
\hline \multirow{2}{*}{ Literacy } & Literate & \multirow{2}{*}{179} & 111 & 62.0 & \multirow{2}{*}{230} & 49 & 21.3 \\
\hline & Illiterate & & 68 & 38.0 & & 181 & 78.7 \\
\hline \multirow{2}{*}{ Co-Residence } & Lives Alone & \multirow{2}{*}{179} & 25 & 14.0 & \multirow{2}{*}{238} & 65 & 27.3 \\
\hline & Lives with other people & & 154 & 86.0 & & 173 & 72.7 \\
\hline \multirow{2}{*}{ Self-reported Ethnicity } & White & \multirow{2}{*}{168} & 91 & 54.2 & \multirow{2}{*}{227} & 140 & 61.7 \\
\hline & Non-white & & 77 & 45.8 & & 87 & 38.3 \\
\hline \multirow{2}{*}{ Marital Status } & With Partner & \multirow{2}{*}{179} & 102 & 57.0 & \multirow{2}{*}{238} & 188 & 79.0 \\
\hline & Without Partner & & 77 & 43.0 & & 50 & 21.0 \\
\hline
\end{tabular}




\begin{tabular}{|c|c|c|c|c|c|c|c|}
\hline \multirow{2}{*}{ Income } & Up to $1 \mathrm{MW}$ & \multirow{2}{*}{176} & 118 & 67.0 & \multirow{2}{*}{204} & 86 & 42.2 \\
\hline & More than $1 \mathrm{MW}$ & & 58 & 33.0 & & 118 & 57.8 \\
\hline \multirow{2}{*}{ Income Sufficiency } & Doesn't consider sufficient & \multirow{2}{*}{177} & 69 & 39.0 & \multirow{2}{*}{225} & 90 & 40.0 \\
\hline & Considers sufficient & & 108 & 61.0 & & 135 & 60.0 \\
\hline \multirow{2}{*}{ Religion } & Has & \multirow{2}{*}{178} & 177 & 0.6 & \multirow{2}{*}{223} & 215 & 3.6 \\
\hline & Doesn't Have & & 1 & 99.4 & & 8 & 96.4 \\
\hline \multirow{3}{*}{ Economic Situation in childhood } & Good & \multirow{3}{*}{160} & 34 & 21.3 & \multirow{3}{*}{224} & 74 & 33.0 \\
\hline & Regular & & 52 & 32.5 & & 100 & 44.6 \\
\hline & $\mathrm{Bad}$ & & 74 & 46.3 & & 50 & 22.4 \\
\hline \multirow{2}{*}{ Starved in Childhood } & Yes, I was hungry & \multirow{2}{*}{162} & 67 & 41.4 & \multirow{2}{*}{223} & 33 & 14.8 \\
\hline & No, I wasn't hungry & & 95 & 58.6 & & 190 & 85.2 \\
\hline \multirow{3}{*}{ Health self-assessment } & $\mathrm{Bad}$ & \multirow{3}{*}{131} & 14 & 10.7 & \multirow{3}{*}{214} & 28 & 13.1 \\
\hline & Regular & & 66 & $\overline{50.4}$ & & 93 & 43.5 \\
\hline & Good & & 51 & 38.9 & & 93 & 43.5 \\
\hline \multirow{3}{*}{ Number of chronic diseases (nDCNT) } & Two or more & \multirow{3}{*}{179} & 94 & 52.5 & \multirow{3}{*}{223} & 164 & 73.5 \\
\hline & One & & 64 & 35.8 & & 42 & 18.8 \\
\hline & None & & 21 & 11.7 & & 17 & 7.6 \\
\hline \multirow{2}{*}{ Depression Symptoms (GDS) } & Suggestion of depression symptoms & \multirow{2}{*}{90} & 38 & 42.2 & \multirow{2}{*}{238} & 118 & 49.6 \\
\hline & No depression symptoms & & 52 & $\overline{57.8}$ & & 120 & 50.4 \\
\hline \multirow{3}{*}{ Number of drugs } & Five or more (Polypharmacy) & & 94 & 52.5 & & 139 & 63.5 \\
\hline & Between 1 and 4 & 179 & 80 & 44.7 & 219 & 80 & 36.5 \\
\hline & None & & 5 & 2.8 & & 0 & 0.0 \\
\hline Physical Astivity (lact 3 months) & Didn’t Practice & 170 & 144 & 80.4 & 235 & 186 & 79.1 \\
\hline 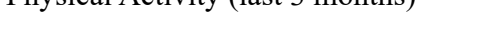 & Practiced & 179 & 35 & 19.6 & 253 & 49 & 20.9 \\
\hline Imnortance of Relioion & Little importance & 168 & 13 & 7.7 & 200 & 24 & 11.5 \\
\hline Importance of Keligion & Important & 168 & 155 & 92.3 & 209 & 185 & 88.5 \\
\hline J eicure Astivity (Walking) & Doesn't do any & & 70 & 41.4 & & 93 & 41.2 \\
\hline Leisure Activity (Walking) & Does & 169 & 99 & 58.6 & 220 & 133 & 58.8 \\
\hline Smoking & Smokes/Has smoked & & 102 & 57.3 & 234 & 83 & 35.5 \\
\hline SIIUKIII & Never smoked & $1 / 0$ & 76 & 42.7 & 254 & 151 & 64.5 \\
\hline & Alone & & 3 & 1.9 & & 75 & 32.5 \\
\hline Sonds Moct of the Timo With & Children and teenagers & & 7 & 4.5 & 231 & 12 & 5.2 \\
\hline spenas inost or the rime with & Adults & 150 & 63 & $\overline{40.4}$ & 251 & 67 & 29.0 \\
\hline & Elderly People & & 83 & 53.2 & & 77 & 33.3 \\
\hline & Alone & & 25 & 14.0 & & 62 & 26.6 \\
\hline & Only Spouse & & 37 & 20.7 & & 29 & 12.4 \\
\hline Family Arrangements & Only Children & 179 & 45 & 25.1 & 233 & 64 & 27.5 \\
\hline & Children and Grandchildren & & 32 & 17.9 & & 41 & 17.6 \\
\hline & Other Arrangements & & 40 & 22.3 & & 37 & 15.9 \\
\hline Receives support & No & 179 & 34 & 19.0 & 237 & 73 & 30.8 \\
\hline Kecerves support & Yes & $1 / 9$ & 145 & 81.0 & 251 & 164 & 69.2 \\
\hline
\end{tabular}




\begin{tabular}{|c|c|c|c|c|c|c|c|}
\hline \multirow{2}{*}{ Gives Support } & No & \multirow{2}{*}{179} & 41 & 22.9 & \multirow{2}{*}{237} & 95 & 40.1 \\
\hline & Yes & & 138 & 77.1 & & 142 & 59.9 \\
\hline \multirow{3}{*}{ Support Network - has someone to count on } & Never & \multirow{3}{*}{137} & 10 & 7.3 & \multirow{3}{*}{205} & 6 & 2.9 \\
\hline & Sometimes & & 16 & 11.7 & & 11 & 5.4 \\
\hline & Always & & 111 & 81.0 & & 188 & 91.7 \\
\hline \multirow{2}{*}{ Domestic Animal (Pet) } & Doesn't have & \multirow{2}{*}{179} & 104 & 58.1 & \multirow{2}{*}{235} & 158 & 67.2 \\
\hline & Has & & 75 & 41.9 & & 77 & 32.8 \\
\hline \multirow{2}{*}{ Interference of the animal in the mood } & Doesn't interfere & \multirow{2}{*}{71} & 18 & 25.4 & \multirow{2}{*}{-76} & 15 & 19.7 \\
\hline & Interferes positively & & 53 & 74.6 & & 61 & 80.3 \\
\hline \multirow{2}{*}{ Importance of the domestic animal (Pet) } & Little importance & \multirow{2}{*}{71} & 21 & 29.6 & \multirow{2}{*}{-75} & 9 & 12.0 \\
\hline & Important & & 50 & 70.4 & & 66 & 88.0 \\
\hline
\end{tabular}

In the Northeast, the elderly lived in poverty and experienced periods of drought that restricted access to food. When the elderly was asked if they "starved" in childhood, $41.4 \%$ of the Northeast population answered affirmatively; this contrasts with $14.8 \%$ of the Southeast population in the same condition (Table 1). Therefore, regional economic asymmetries are associated with social inequalities between the two groups studied.

Despite differences in material and educational conditions, the indexes of happiness, subjective well-being, and overall life satisfaction are very similar in both populations studied, with $71.9 \%$ (rural Northeast) and $72 \%$ (urban Southeast) for happiness; $76.9 \%$ (rural) and $78.7 \%$ (urban) for better subjective well-being, and $87.1 \%$ (rural) and $80.8 \%$ (urban) for overall life satisfaction. There are practically no differences in the proportion of elderly people who experience happiness, subjective well-being, and overall life satisfaction between both groups (Table 1).

Regarding health conditions, the two populations show significant differences. More than half of the older elderly people in the Northeast (61.1\%) and Southeast (56.6\%) rate their health status as fair or poor; $73.5 \%$ of the elderly in urban areas have one or more chronic diseases and $63.5 \%$ of them use more than five drugs. In rural areas, $52.5 \%$ of the elderly have one or more chronic diseases and use polypharmacy. Regarding mental health, the results are similar: $42.2 \%$ of the older elderly people in the Northeast and $49.6 \%$ in the Southeast showed symptoms suggestive of depression.

Regarding whether they have religion, most of the older elderly people in this study have religion $(99 \%$ in the NE and $96.4 \%$ in the SE). In relation to the practice of physical activity, most practice some leisure activity, such as walking (58.6\% in the NE and $58.8 \%$ in the SE). In the urban region, there was a higher proportion of elderly people who reported having someone to turn to when they needed it $(91.7 \%)$ than in the rural region (81\%), receiving financial and material support, personal care and tasks, emotional support and companionship. In the Southeast, $30.8 \%$ of the elderly reported living alone and not having support from anyone compared, to $19 \%$ in the Northeast.

In the Northeast, the elderly lives more with other elderly (53.2\%) and more adults (40.4\%) in their daily lives than in the Southeast (33.3\% and 29\%, respectively). The configuration of family arrangements shows us that in the urban center of the Southeast $26.6 \%$ of the elderly live alone and $75.4 \%$ live with other people. Most of them live with only their children $(27.5 \%)$, or with only a spouse (12.4\%), with children and grandchildren $(17.6 \%)$ or have other arrangements (15.9\%). In the rural Northeast, only $14 \%$ of the elderly live alone. Of the $86 \%$ who live with other people, most live with their children (25.1\%), their spouses $(20.7 \%)$, children and grandchildren (17.9\%) or have other arrangements ( $22.3 \%$ ). Regarding the presence of animals in the home and their influence on the mood of the elderly, the elderly in the Northeast have more domestic animals (pets)(41.9\%) than those in the Southeast $(32.8 \%)$, showing their positive influence on mood more $(74.6 \%)$ in relation to the urban population $(80.3 \%)$ (Table 1).

Table 2 shows the gross and adjusted values of factors associated with happiness among the elderly in the Northeast and among the elderly in the Southeast. In both populations, the absence of symptoms suggestive of depression was a predictor of happiness; In the Northeast, this group is 8.06 times more likely to feel happy than those with depressive symptoms, while in the Southeast those without these symptoms are 3.73 times more likely to feel happy.

In the Northeast, three more variables were associated with happiness, the most important of which was the 
support network. More than $80 \%$ of the Northeast's older elderly people said they had someone to turn to when they needed to. Older people who receive support from their family or friends are 27.46 times more likely to feel happy than those who do not. Those who live with a partner feel happier than those without a partner. Elderly people who practice leisure activities, such as walking, are 5.28 more likely to feel happy than non-practitioners (Table 2).

In the Southeast, the results were quite different, as no other variable besides the absence of depressive symptoms was associated with happiness, as shown in Table 2.

The results for the association study with the dependent variable subjective well-being were shown in Table 3 . In this case, for the Northeast population, the only variable that had a significant association was self-assessed health. Elderly people with good self-assessed health are 5.51 more likely to have better subjective well-being than those who report their own health as regular or bad. For most of the other variables it was not possible to obtain the value of odds ratio.

For the Southeast population, marital status, income sufficiency and absence of depressive symptoms were associated with the dependent variable. In this region, elderly people with no symptoms suggestive of depression are 9.43 more likely to have better subjective well-being than the group with symptoms. Those who live with their partners, being married or living together, are 5.77 more likely to have better subjective well-being than the single, widowed, separated, or divorced. Those with income sufficiency are 3.2 more likely to also have a better perception of well-being.

Table 4 presents the results found from the analytical point of view for the dependent variable overall life satisfaction, and it can be verified that no odds ratio results were obtained for some of the independent variables. For the Southeast region, again it was found that the elderly who do not have symptoms suggestive of depression are 6.29 more likely to be satisfied with their life. Elderly people with good support network are 9.3 times more likely to be more satisfied with life than those who reported never receiving support. In the Northeast region, the factor that showed a strong association with life satisfaction was the practice of leisure activity. Elderly people who perform walking or walking activities are 8.1 times more likely to be satisfied with life than those who do not (Table 4). 
Table 2. Multiple logistic regression model for the association between happiness and sociodemographic, health, and lifestyle aspects of older elderly people living in the Northeast (SABE-PB) and Southeast (SABE-SP) of Brazil

\begin{tabular}{|c|c|c|c|c|c|c|c|c|c|c|c|c|}
\hline & \multirow{4}{*}{$\begin{array}{l}\text { Less } \\
\text { happy } \\
\text { N(\%) }\end{array}$} & \multicolumn{3}{|c|}{ HAPPINESS - SABE-PB } & \multicolumn{8}{|c|}{ HAPPINESS- SABE-SP } \\
\hline & & More & OR & & OR & & Less & More & OR & & OR & \\
\hline & & happy & gross & $\mathbf{p}$ & ajusted & $\mathbf{p}$ & happy & happy & gross & $\mathbf{p}$ & Ajusted & $\mathbf{p}$ \\
\hline & & $\mathbf{N}(\%)$ & (IC 95\%) & & (IC 95\%) & & $\mathbf{N}(\%)$ & $\mathbf{N}(\%)$ & (IC 95\%) & & (IC 95\%) & \\
\hline Gender & & & & 0.147 & & 0.154 & & & & 0.130 & & 0.128 \\
\hline Feminine & $26(37)$ & $44(63)$ & 1 & & 1 & & $38(26)$ & $107(74)$ & 1 & & 1 & \\
\hline Masculine & $12(18)$ & $53(82)$ & $2.43(0.86-6.84)$ & & $2.64(0.7-10.03)$ & & $20(32)$ & $43(68)$ & $2.32(1.06-5.09)$ & & $2.07(0.81-5.26)$ & \\
\hline Literacy & & & & 0.097 & & 0.117 & & & & & & \\
\hline Yes & $14(25)$ & $43(75)$ & $2.06(0.71-6.01)$ & & $3.58(0.73 .17 .7)$ & & $41(25)$ & $126(75)$ & & & & \\
\hline No & $24(31)$ & $54(69)$ & 1 & & 1 & & $17(45)$ & $21(55)$ & & & & \\
\hline Co-residence & & & & 0.02 & & 0.029 & & & & & & \\
\hline Lives alone & $7(29)$ & $17(71)$ & 1 & & 1 & & $16(26)$ & $45(74)$ & & & & \\
\hline Lives With Others & $31(28)$ & $80(72)$ & $\begin{array}{c}0.69 \\
(0.18-2.75)\end{array}$ & & $0.03(0-0.7)$ & & $42(29)$ & $105(71)$ & & & & \\
\hline Ethnicity & & & & 0.24 & & 0.25 & & & & & & \\
\hline White & $15(22)$ & $52(78)$ & $1.85(0.67-5.09)$ & & $2.23(0.56-8.89)$ & & $35(27)$ & $93(73)$ & & & & \\
\hline Non white & $21(33)$ & $43(67)$ & 1 & & 1 & & $23(29)$ & $56(71)$ & & & & \\
\hline Economic Situation in childhood & & & & 0.318 & & 0.135 & & & & $<0.001$ & & 0.104 \\
\hline Good & $10(33)$ & $20(67)$ & $0.65(0.18-2.31)$ & & $0.27(0.05-1.51)$ & & $10(14)$ & $61(86)$ & $\begin{array}{l}4.33 \\
(1.48-12.66)\end{array}$ & & $\begin{array}{l}2.87 \\
(0.81-10.24)\end{array}$ & \\
\hline Regular & $13(33)$ & $26(67)$ & $0.83(0.26-2.68)$ & & $0.61(0.13-2.88)$ & & $32(36)$ & $58(64)$ & $0.89(0.39-2.01)$ & & $0.44(0.15-1.3)$ & \\
\hline Bad & $15(23)$ & $50(77)$ & 1 & & 1 & & $16(35)$ & $30(65)$ & 1 & & 1 & \\
\hline Insufficiency of food up to 15 Years & & & & - & & - & & & & 0.613 & & 0.611 \\
\hline Yes & $17(31)$ & $37(69)$ & - & & - & & $10(36)$ & $18(64)$ & 1 & & 1 & \\
\hline No & $21(26)$ & $59(74)$ & - & & - & & $47(26)$ & $132(74)$ & $1.53(0.6-3.86)$ & & $1.35(0.42-4.34)$ & \\
\hline Number of chronic diseases & & & & 0.117 & & 0.062 & & & & & & \\
\hline
\end{tabular}




\begin{tabular}{|c|c|c|c|c|c|c|c|c|c|c|c|c|}
\hline$(\mathrm{nDCNT})$ & & & & & & & & & & & & \\
\hline Two or more & $21(30)$ & $48(70)$ & 1 & & 1 & & $37(26)$ & $107(74)$ & & & & \\
\hline One & $13(25)$ & $38(75)$ & $1.11(0.38-3.27)$ & & $0.19(0.03-1.09)$ & & $11(28)$ & $28(72)$ & & & & \\
\hline None & $4(27)$ & $11(73)$ & $1.36(0.31-5.9)$ & & $0.68(0.09-5.21)$ & & $6(40)$ & $9(60)$ & & & & \\
\hline Depression Symptoms & & & & 0.011 & & 0.006 & & & & 0.001 & & $<0.001$ \\
\hline Yes & $15(41)$ & $22(59)$ & 1 & & 1 & & $38(43)$ & $51(57)$ & 1 & & 1 & \\
\hline No & $8(16)$ & $42(84)$ & $\begin{array}{l}3.64 \\
(1.28-10.35)\end{array}$ & & $8.06(1.6-40.48)$ & & $20(167)$ & $99(83)$ & $3.66(1.8-7.44)$ & & $3.73(1.68-8.26)$ & \\
\hline Importance of Religion & & & & 0.065 & & 0.053 & & & & & & \\
\hline Little importance & $3(30)$ & $7(70)$ & 1 & & 1 & & $7(29)$ & $17(71)$ & & & & \\
\hline Important & $34(28)$ & $89(72)$ & $1.53(0.26-9)$ & & $8.83(0.97-79.96)$ & & $50(28)$ & $126(72)$ & & & & \\
\hline Leisure Activity (Walking) & & & & 0.024 & & 0.03 & & & & & & \\
\hline Doesn't perform & $20(43)$ & $27(57)$ & 1 & & 1 & & $22(29)$ & $53(71)$ & & & & \\
\hline Performs & $18(20)$ & $70(80)$ & $3.43(1.2-9.81)$ & & $5.28(1.17-23.83)$ & & $33(26)$ & $96(74)$ & & & & \\
\hline Receives support & & & & 0.02 & & 0.027 & & & & & & \\
\hline Yes & $28(26)$ & $79(74)$ & $1.3(0.4-4.26)$ & & $\begin{array}{l}27.46 \\
(1.44-521.92)\end{array}$ & & $40(28)$ & 101(72) & & & & \\
\hline No & $10(36)$ & $18(64)$ & 1 & & 1 & & $18(27)$ & $49(73)$ & & & & \\
\hline Support Network & & & & - & & - & & & & & & 0.157 \\
\hline Never & 0 & 0 & - & & - & & $3(50)$ & $3(50)$ & 1 & & 1 & \\
\hline Sometimes & $4(27)$ & $11(73)$ & - & & - & & $6(55)$ & $5(45)$ & & & & \\
\hline Always & $24(24)$ & $75(76)$ & - & & - & & $44(24)$ & $141(76)$ & $2.55(0.65-9.97)$ & 0.122 & $3.35(0.72-15.52)$ & \\
\hline
\end{tabular}


Table 3. Multiple logistic regression model for the association between subjective well-being and sociodemographic, health and lifestyle aspects of older elderly people in the Northeast (SABE-PB) and Southeast (SABE-SP) of Brazil

\begin{tabular}{|c|c|c|c|c|c|c|c|c|c|c|c|c|}
\hline & \multirow{4}{*}{$\begin{array}{l}\text { Worse SWB } \\
\mathrm{N}(\%)\end{array}$} & \multicolumn{5}{|c|}{ SUBJECTIVE WELL-BEING (SWB) - SABE-PB } & \multicolumn{6}{|c|}{ SUBJECTIVE WELL-BEING (SWB) - SABE-SP } \\
\hline & & \multirow{3}{*}{$\begin{array}{l}\text { Best SWB } \\
\text { N(\%) }\end{array}$} & \multirow{2}{*}{$\begin{array}{l}\text { OR } \\
\text { gross }\end{array}$} & \multirow{3}{*}{$\mathbf{P}$} & \multirow{3}{*}{$\begin{array}{l}\text { OR } \\
\text { ajusted } \\
\text { (IC 95\%) }\end{array}$} & \multirow{3}{*}{$\mathbf{p}$} & \multirow{3}{*}{$\begin{array}{l}\text { Worse SWB } \\
\text { N(\%) }\end{array}$} & \multirow{3}{*}{$\begin{array}{l}\text { Best SWB } \\
\text { N(\%) }\end{array}$} & \multirow{2}{*}{$\begin{array}{l}\text { OR } \\
\text { gross }\end{array}$} & \multirow{3}{*}{$\mathbf{P}$} & \multirow{2}{*}{$\frac{\mathrm{OR}}{\text { ajusted }}$} & \multirow{3}{*}{$\mathbf{p}$} \\
\hline & & & & & & & & & & & & \\
\hline & & & (IC 95\%) & & & & & & (IC 95\%) & & (IC 95\%) & \\
\hline Literacy & & & & 0.923 & & 0.923 & & & & & & \\
\hline Yes & $13(23)$ & $43(77)$ & $0.92(0.38-2.26)$ & & $1.05(0.39-2.79)$ & & $32(20)$ & $129(80)$ & & & & \\
\hline No & $18(23)$ & $60(77)$ & 1 & & 1 & & $10(26)$ & $28(74)$ & & & & \\
\hline Ethnicity & & & & 0.903 & & 0.903 & & & & & & \\
\hline White & $16(23)$ & $55(77)$ & $1.06(0.43-2.58)$ & & $1.06(0.4-2.79)$ & & $22(18)$ & $102(82)$ & & & & \\
\hline Non white & $13(22)$ & $46(78)$ & 1 & & 1 & & $21(27)$ & $56(73)$ & & & & \\
\hline Marital status & & & & - & & - & & & & 0.023 & & 0.031 \\
\hline No partner & $21(30)$ & $49(70)$ & - & & - & & $37(23)$ & $121(77)$ & 1 & & 1 & \\
\hline With partner & $10(16)$ & $54(84)$ & - & & - & & $6(14)$ & $38(86)$ & $2(0.73-5.53)$ & & $5.77(1.18-28.33)$ & \\
\hline Income Sufficiency & & & & 0.434 & & 0.44 & & & & 0.035 & & $\mathbf{0 . 0 3 7}$ \\
\hline Yes & $20(24)$ & $64(76)$ & $0.89(0.36-2.25)$ & & $0.67(0.24-1.85)$ & & $18(15)$ & $106(85)$ & $3.4(1.63-7.11)$ & & $3.2(1.07-9.52)$ & \\
\hline No & $11(22)$ & $39(78)$ & 1 & & 1 & & $25(33)$ & $50(67)$ & 1 & & 1 & \\
\hline Insufficient food up to 15 Years & & & & - & & - & & & & 0.201 & & 0.199 \\
\hline Yes & $18(32)$ & $38(68)$ & - & & - & & $8(30)$ & $19(70)$ & 1 & & 1 & \\
\hline No & $13(17)$ & $62(83)$ & - & & - & & $35(20)$ & $140(80)$ & $1.71(0.65-4.49)$ & & $2.38(0.63-8.95)$ & \\
\hline Self-assessment of health & & & & 0.062 & & 0.037 & & & & $<0.001$ & & 0.926 \\
\hline $\mathrm{Bad}$ & $5(45)$ & $6(55)$ & 1 & & 1 & & $18(67)$ & $9(33)$ & 1 & & 1 & \\
\hline Regular & $16(27)$ & $43(73)$ & $1.82(0.45-7.36)$ & & $2.08(0.49-8.84)$ & & $16(18)$ & $73(82)$ & $0.12(0.05-0.32)$ & & $0.11(0.03-0.41)$ & \\
\hline Good & $6(13)$ & $41(87)$ & $4.56(1.02-20.99)$ & & $5.51(1.1-27.5)$ & & $8(9)$ & $77(91)$ & $2.69(0.99-7.34)$ & & $0.94(0.28-3.24)$ & \\
\hline Depression Symptoms & & & & - & & - & & & & $<0.001$ & & $<0.001$ \\
\hline Yes & $12(34)$ & $23(66)$ & - & & - & & $35(43)$ & $47(57)$ & 1 & & 1 & \\
\hline
\end{tabular}




\begin{tabular}{|c|c|c|c|c|c|c|c|c|c|c|}
\hline No & $7(14)$ & $43(86)$ & - & - & $8(7)$ & $112(93)$ & $8.69(3.69-20.47)$ & & $9.43(3.02-29.42)$ & \\
\hline Physical Activity (last 3 months) & & & & - & - & & & 0.253 & & 0.27 \\
\hline Didn’t do any & $27(26)$ & $78(74)$ & - & - & $39(25)$ & $114(75)$ & 1 & & 1 & \\
\hline Did & $4(14)$ & $25(86)$ & - & - & $4(8)$ & $45(92)$ & $3.32(1.11-9.94)$ & & $2.28(0.53-9.88)$ & \\
\hline Importance of Religion & & & & - & - & & & 0.756 & & 0.755 \\
\hline Little importance & $3(30)$ & $7(70)$ & - & - & $6(26)$ & $17(74)$ & 1 & & 1 & \\
\hline Important & $28(23)$ & $94(77)$ & - & - & $35(20)$ & $136(80)$ & $1.42(0.52-3.9)$ & & $1.26(0.29-5.52)$ & \\
\hline Leisure Activity (Walking) & & & & - & - & & & 0.083 & & 0.086 \\
\hline Doesn't perform & $16(33)$ & $32(67)$ & - & - & $24(35)$ & $44(65)$ & 1 & & 1 & \\
\hline Performs & $14(16)$ & $71(84)$ & - & - & $16(12)$ & $113(88)$ & $3.52(1.68-7.37)$ & & $2.56(0.88-7.48)$ & \\
\hline Domestic Animal (Pet) & & & & - & - & & & 0.102 & & 0.104 \\
\hline Doesn't Have & $16(21)$ & $62(79)$ & - & - & $22(17)$ & $108(83)$ & 1 & & 1 & \\
\hline Has & $15(27)$ & $41(73)$ & - & - & $21(30)$ & $50(70)$ & $0.5(0.24-1.02)$ & & $0.42(0.15-1.19)$ & \\
\hline
\end{tabular}

Table 4. Multiple logistic regression model for the association between overall life satisfaction and sociodemographic, health and lifestyle aspects of older elderly people living in Northeast (SABE-PB) and Southeast (SABE-SP) Brazil

\begin{tabular}{|c|c|c|c|c|c|c|c|c|c|c|c|c|}
\hline & \multicolumn{6}{|c|}{ Overall Life Satisfaction (OLS) - SABE-PB } & \multicolumn{6}{|c|}{ Overall Life Satisfaction (OLS) - SABE-SP } \\
\hline & $\begin{array}{l}\text { Low OLS } \\
\mathrm{N}(\%)\end{array}$ & $\begin{array}{l}\text { High OLS } \\
\text { N(\%) }\end{array}$ & $\begin{array}{l}\text { OR gross } \\
\text { (IC 95\%) }\end{array}$ & $\mathbf{p}$ & $\begin{array}{l}\text { OR adjusted } \\
\text { (IC 95\%) }\end{array}$ & $\mathbf{p}$ & $\begin{array}{l}\text { Low OLS } \\
\text { N(\%) }\end{array}$ & $\begin{array}{l}\text { High OLS } \\
\text { N(\%) }\end{array}$ & $\begin{array}{l}\text { OR gross } \\
\text { (IC 95\%) }\end{array}$ & $\mathbf{p}$ & OR ajusted (IC 95\%) & $\mathbf{p}$ \\
\hline Gender & & & & - & & - & & & & 0.436 & & 0.442 \\
\hline Feminine & $11(15)$ & $61(85)$ & - & & - & & $33(21)$ & $126(79)$ & 1 & & 1 & \\
\hline Masculine & $7(10)$ & $61(90)$ & - & & - & & $10(15)$ & $55(85)$ & $1.42(0.64-3.14)$ & & $1.44(0.57-3.67)$ & \\
\hline Literacy & & & & - & & - & & & & 0.438 & & 0.433 \\
\hline Yes & $8(14)$ & $50(86)$ & - & & - & & $31(18)$ & $142(82)$ & $1.64(0.69-3.88)$ & & $1.52(0.54-4.29)$ & \\
\hline No & $10(12)$ & $72(88)$ & - & & - & & $11(24)$ & $34(76)$ & 1 & & 1 & \\
\hline Co-residence & & & & 0.053 & & 0.053 & & & & 0.371 & & 0.369 \\
\hline
\end{tabular}




\begin{tabular}{|c|c|c|c|c|c|c|c|c|c|c|c|c|}
\hline Lives alone & $5(20)$ & $20(80)$ & 1 & & 1 & & $11(17)$ & $52(83)$ & 1 & & 1 & \\
\hline Lives with others & $13(11)$ & $102(89)$ & $3.81(1.04-14.02)$ & & $4.71(0.98-22.64)$ & & $32(20)$ & $129(80)$ & $0.82(0.37-1.81)$ & & $0.46(0.08-2.52)$ & \\
\hline Health self-assessment & & & & - & & - & & & & 0.215 & & 0.180 \\
\hline $\mathrm{Bad}$ & $3(21)$ & $11(79)$ & - & & - & & $12(43)$ & $16(57)$ & 1 & & 1 & \\
\hline Regular & $7(11)$ & $55(89)$ & - & & - & & $20(22)$ & $71(78)$ & $0.43(0.17-1.07)$ & & $0.74(0.25-2.15)$ & \\
\hline Good & $6(12)$ & $44(88)$ & - & & - & & $11(12)$ & $81(88)$ & $2.4(1.02-5.68)$ & & $2.01(0.72-5.56)$ & \\
\hline Depression Symptoms & & & & 0.567 & & 0.567 & & & & $<0.001$ & & $<0.001$ \\
\hline Yes & $7(19)$ & $30(81)$ & 1 & & 1 & & $34(33)$ & $70(67)$ & 1 & & 1 & \\
\hline No & $5(10)$ & $46(90)$ & $2.15(0.62-7.39)$ & & $1.54(0.35-6.76)$ & & $9(8)$ & $111(92)$ & $7.43(3.28-16.85)$ & & $6.29(2.54-15.59)$ & \\
\hline Importance of Religion & & & & 0.151 & & $0-133$ & & & & & & \\
\hline Little importance & $3(27)$ & $8(73)$ & 1 & & 1 & & $6(25)$ & $18(75)$ & & & & \\
\hline Important & $15(12)$ & $112(88)$ & $0.35(0.06-2.06)$ & & $0.19(0.02-1.66)$ & & $36(20)$ & $144(80)$ & & & & \\
\hline Leisure Activity (Walking) & & & & 0.008 & & 0.012 & & & & & & \\
\hline Doesn't perform & $10(21)$ & $38(79)$ & 1 & & 1 & & $20(24)$ & $64(76)$ & & & & \\
\hline Performs & $8(9)$ & $83(91)$ & $3.47(1.02-12.16)$ & & $8.1(1.6-41.13)$ & & $21(16)$ & $110(84)$ & & & & \\
\hline Smoking & & & & 0.081 & & 0.102 & & & & & & \\
\hline Smoked/Has smoked & $14(18)$ & $63(82)$ & 1 & & 1 & & $18(23)$ & $61(77)$ & & & & \\
\hline Never smoked & $4(6)$ & $59(94)$ & $2.43(0.61-9.68)$ & & $3.83(0.77-19.21)$ & & $25(17)$ & $118(83)$ & & & & \\
\hline Support network & & & & - & & - & & & & 0.008 & & 0.004 \\
\hline Never & 0 & 0 & - & & - & & $2(33)$ & $4(67)$ & 1 & & 1 & \\
\hline Sometimes & $2(13)$ & $13(87)$ & - & & - & & $7(64)$ & $4(36)$ & $3.5(0.43-28.45)$ & & $2.99(0.25-35.39)$ & \\
\hline Always & $14(14)$ & $89(86)$ & - & & - & & $31(17)$ & $155(83)$ & $8.58(2.36-31.14)$ & & $9.3(2.07-41.79)$ & \\
\hline
\end{tabular}




\section{Discussion}

For the first time in Brazil, this study compared two populations of older elderly people with very different profiles in relation to sociodemographic, health and lifestyle aspects, in order to investigate how these differences could influence the perception of happiness, subjective well-being, and life satisfaction. In the Northeast, the older elderly people have lower incomes and had little access to formal education, and part of them suffered from childhood food restriction. These restrictions, however, do not seem to have negatively influenced the perceptions of the elderly people aged 80 or older to the point where they feel less happy, less well-being, or dissatisfied with their lives compared to elderly people in a large urban center. The prevalence of these feelings was not different between the two populations despite the evident socioeconomic differences.

These results corroborate other studies that did not associate happiness and income (Easterlin, 2003; Lawrence, Rogers, \& Wadsworth, 2015). On the other hand, the findings of this paper differ from a study in Germany, where low socioeconomic status was a robust and independent risk factor for low subjective well-being in both genders, thus highlighting the detrimental effect of severe economic constraints on elderly people (Lukaschek, Vanajan, Johar, Weiland, \& Ladwig, 2017). The southeastern population is more diverse in relation to literacy than the Northeastern, and for this reason, the results corroborate literature, verifying the association between literacy and subjective well-being (Blanchflower \& Oswald, 2000).

In the studied population, there is a higher prevalence in the Northeast of Brazil of men aged 80 years or older than in the Southeast, as well as more elderly people living with their spouses and fewer older people living alone; the support network for the elderly was one of the factors most strongly associated with the perception of happiness. In the Southeast, the elderly were found to be lonelier; however, those who live with a partner have a better perception of subjective well-being. These results corroborate findings in literature showing an association between marital status and happiness, subjective well-being and life satisfaction (Haring-Hidore, Stock, Okun, \& Witter, 1985; Lucas, Clark, Georgellis, \& Diener, 2003; Veenhoven, 2005; Marks \& Fleming, 1997). Regarding the support network, a longitudinal study conducted in England (Rafnsson, Shankar, \& Steptoe, 2015) showed that the size of the social network and the frequency of network contact were positively and independently associated with life satisfaction and quality of life. That is, frequent contact with other people is important for the elderly to feel more satisfaction with life.

In the Northeast, there was a positive association between leisure activities, such as walking, and life satisfaction. These results corroborate other studies conducted in the United States (Chang, Wray, \& Lin, 2014; Ragheb \& Griffith, 1982). In addition, the elderly interviewed in this paper reported that domestic animals (pets) contribute positively to mood enhancement. Although no associations were found between the presence of domestic animals (pets) and feeling happier and more satisfied with life, frequency data show a tendency towards that. Some studies have already suggested the potential benefits of animals on physical and psychological health in humans (Cherniack, Paul Cherniack, \& Cherniack, 2014); and others, specifically from a cohort of the elderly, demonstrated that owning animals was associated with improved cardiovascular disease survival in a hypertensive population (Chowdhury, Nelson, Jennings, Wing, \& Reid, 2017).

The self-assessed health indicator is a widely used and recommended tool in studies with the elderly to understand the aspects that influence it and its relationship with well-being (Confortin, Giehl, Antes, Schneider, \& d'Orsi, 2015). A Korean study revealed that better self-assessed health increases life satisfaction (Lee, Choi, \& Lee, 2020). Elderly people in the Northeast reported having suffered food restrictions in childhood due to poverty. Overcoming these difficulties and being older may have contributed to better acceptance of current health conditions, awakening an overall sense of positive happiness and subjective well-being.

Another factor that contributes significantly to the improvement of these perceptions is the absence of symptoms suggestive of depression. In the elderly, the development of depression is common, mainly because, over the years, the number of successive losses of loved ones and the withdrawal from their daily activities lead the elderly to question about life and its meaning. These questions may or may not lead the elderly to the construction of new meanings in life, which may happen from the creation and execution of a job or practice of an act; experiencing something or finding someone to love; or by the attitude towards suffering that cannot be changed (Frankl, 2013). For this reason, family members and others who make up the elderly support network should be aware of signs of loss of interest in performing daily activities and the desire for isolation, as well as other signs of depression. A Korean study showed that emotional support from family and/or friends attenuated the negative influence of life satisfaction events. The results revealed that the life satisfaction trajectories of the elderly increased with maturity and good family relationships (Lee, Choi, \& Lee, 2020).

The study has its limitations, such as the cross-sectional design itself that does not allow associations of cause and 
effect. The analyses performed are not intended to define the origin of the results found, but to explore the factors associated with the variables in the two different regions studied, contributing to expose the importance of studying health indicators related to subjective health. It is noteworthy that the international studies brought to discuss the studied aspects present different cultural issues, which limits the comparison with our results. Another limitation concerns the population itself that has an advanced age and low cognition, and sometimes needs an auxiliary informant to answer some questions, which may cause some bias. In addition, it was not possible to perform statistical analysis for many of the Northeast population variables, which may be improved in the near future.

Regarding the sampling methods, because the surveys were financiered by two different funding agencies (FAPESP and CAPES/CNPq), data was collected in different years (2015 and 2017). In Brejo dos Santos, the totality of seniors aged 80 or older was included in the study while, in São Paulo, the sample was randomly chosen, being probabilistic and representative of the population. The SABE questionnaire has been used for many years, having been validated previously; and a few adaptations was performed for its application in Brejo dos Santos. This population was selected by convenience, because the health workers had already participated in a previous research (Lopes et al., 2017).

\section{Conclusion}

The prevalence of feelings of happiness, subjective well-being, and overall life satisfaction were very similar for the older elderly in the Northeast and southeast of Brazil. However, different factors were associated with these perceptions in each region. While in the Southeast, the predictive factors were literacy, higher income, and better economic situation, with many elderly people living alone, in the Northeast the affective ties with more people seem to predominate, as well as having a more frequent and diverse support network, and practice leisure activities.

Our findings allows us to broaden the health view of elderly populations with different lifestyles, seeking to understand which bio-psycho-social factors are inserted in the contexts in which they live, and how health polices can contribute to the promotion of new practices appropriate to each reality, in order to provide the elderly with a better quality of life and healthy long life within their means in their territory.

\section{Acknowledgments}

The current study was funded by Universidade Estadual da Paraíba (PROPESQ), Fundação de Apoio à Pesquisa do Estado da Paraíba (FAPESQ/CNPq - PPSUS 015/2014); CAPES/CNPq (INCT 14/50931-3; 465355/2014-5), Fundação de Amparo à Pesquisa do Estado de São Paulo (FAPESP-CEPID 2013/08028-1; 1999/05125, 2005/54947-2, 2009/53778-3).

\section{Competing Interests Statement}

The authors declare that there are no competing or potential conflicts of interest.

\section{References}

Blanchflower, D. G., \& Oswald, A. J. (2000). Well-being over time in Britain and the USA. National Bureau of Economic Research. NBER Working Paper No., 7487. https://doi.org/10.3386/w7487

Cantril, H. (1966). The pattern of human concerns. New Brunswick, N.J.: Rutgers University Press.

Chang, P.-J., Wray, L., \& Lin, Y. (2014). Social relationships, leisure activity, and health in older adults. Health Psychology, 33(6), 516-523. https://doi.org/10.1037/hea0000051

Cherniack, E. P., Paul Cherniack, E., \& Cherniack, A. R. (2014). The Benefit of Pets and Animal-Assisted Therapy to the Health of Older Individuals. Current Gerontology and Geriatrics Research, 2014, 1-9. https://doi.org/10.1155/2014/623203

Chowdhury, E. K., Nelson, M. R., Jennings, G. L. R., Wing, L. M. H., \& Reid, C. M. (2017). Pet ownership and survival in the elderly hypertensive population. Journal of Hypertension, 35(4), 769-775. https://doi.org/10.1097/HJH.0000000000001214

Confortin, S. C., Giehl, M. W. C., Antes, D. L., Schneider, I. J. C., \& d'Orsi, E. (2015). Positive self-rated health in the elderly: a population-based study in the South of Brazil. Cadernos de Saúde Pública, 31(5), 1049-1060. https://doi.org/10.1590/0102-311X00132014

Diener, E., \& Tay, L. (2015). Subjective well-being and human welfare around the world as reflected in the Gallup World Poll. Int J Psychol., 50(2), 135-149. https://doi.org/10.1002/ijop.12136 
Easterlin, R. A. (2003). Explaining happiness. PNAS, 100(19), 11176-11183. https://doi.org/10.1073/pnas.1633144100

Frankl, V. E. (2013). Em busca de sentido: um psicólogo no campo de concentração. São Leopoldo (SP): Sinodal; Petrópolis (RJ): Vozes. Portuguese.

Haring-Hidore, M., Stock, W. A., Okun, M. A., \& Witter, R. A. (1985). Marital Status and Subjective Well-Being: A Research Synthesis. Journal of Marriage and the Family, 47(4), 947-953. https://doi.org/10.2307/352338

Lawrence, E. M., Rogers, R. G., \& Wadsworth, T. (2015). Happiness and longevity in the United States. Social Science \& Medicine, 145, 115-119. https://doi.org/10.1016/j.socscimed.2015.09.020

Lebrão, M. L., \& Laurenti, R. (2005). Saúde, bem-estar e envelhecimento: o estudo SABE no Município de São Paulo. Rev. bras. epidemiol., 8(2), 127-141. https://doi.org/10.1590/S1415-790X2005000200005

Lee, S. W., Choi, J. S., \& Lee, M. (2020). Life Satisfaction and Depression in the Oldest Old: A Longitudinal Study. Int J Aging Hum Dev., 91(1), 37-59. https://doi.org/10.1177/0091415019843448

Lopes, F. R. L., Monteiro, K. S., Figueiredo, T., Wanderley, T. D. C., de Almeida Pequeno, T., Lima, S., \& Santos, S. (2017). Reliability of information on people with disabilities gathered by community health workers in highly consanguineous communities of northeastern Brazil. BMC Health Serv Res, 17(317), 1-9. https://doi.org/10.1186/s12913-017-2267-3

Lucas, R. E., Clark, A. E., Georgellis, Y., \& Diener, E. (2003). Reexamining adaptation and the set point model of happiness: reactions to changes in marital status. Journal of Personality and Social Psychology, 84(3), 527-539. https://doi.org/10.1037/0022-3514.84.3.527

Lukaschek, K., Vanajan, A., Johar, H., Weiland, N., \& Ladwig, K.-H. (2017). In the mood for ageing: determinants of subjective well-being in older men and women of the population-based KORA-Age study. BMC Geriatrics, 17(1), 126. https://doi.org/10.1186/s12877-017-0513-5

Lyubomirsky, S., \& Lepper, H. S. (1997). Subjective Happiness Scale. PsycTESTS Dataset. https://doi.org/10.1037/t01588-000

Marks, G. N., \& Fleming, N. (1999) Influences and Consequences of Well-being Among Australian Young People: 1980-1995. Social Indicators Research, 46, 301-323. https://doi.org/10.1023/A:1006928507272

Miranda, G. M. D., da Cruz Gouveia Mendes, A., \& da Silva, A. L. A. (2017). Desafios das políticas públicas no cenário de transição demográfica e mudanças sociais no Brasil. Interface (Botucatu), 21(61), 309-320. https://doi.org/10.1590/1807-57622016.0136 (In Portuguese).

OPAS, Organização Pan-Americana da Saúde (US). Saúde nas Américas +: edição de 2017: resumo do panorama regional e perfil do Brasil. Washington, D.C.: http://iris.paho.org/xmlui/bitstream/handle/123456789/34323/9789275719671_por.pdf?sequence=8\&isAllo wed $=\mathrm{y}$. Portuguese

Rafnsson, S. B., Shankar, A., \& Steptoe, A. (2015). Longitudinal Influences of Social Network Characteristics on Subjective Well-Being of Older Adults: Findings From the ELSA Study. Journal of Aging and Health, 27(5), 919-934. https://doi.org/10.1177/0898264315572111

Ragheb, M. G., \& Griffith, C. A. (1982). The Contribution of Leisure Participation and Leisure Satisfaction to Life Satisfaction of Older Persons. Journal of Leisure Research, 14(4), 295-306. https://doi.org/10.1080/00222216.1982.11969527

Veenhoven, R. (2005). Is Happiness a Trait?. In Michalos A. C. (eds.), Citation Classics from Social Indicators Research. Social Indicators Research Series, 26. Springer, Dordrecht. https://doi.org/10.1007/1-4020-3742-2_17

Veenhoven, R. (2015). Greater Happiness for a Greater Number: Did the Promise of Enlightenment Come True? Social Indicators Research, 130(1), 9-25. https://doi.org/10.1007/s11205-015-1128-x

\section{Copyrights}

Copyright for this article is retained by the author(s), with first publication rights granted to the journal.

This is an open-access article distributed under the terms and conditions of the Creative Commons Attribution license (http://creativecommons.org/licenses/by/4.0/). 